\title{
PHYSICOCHEMICAL PROPERTIES OF A LIQUID ION EXCHANGER MICROELECTRODE AND ITS APPLICATION TO BIOLOGICAL FLUIDS
}

\author{
Mamoru Fujimoto and Takahiro Kuвota \\ Department of Physiology, Osaka Medical College, Daigakumachi 2-7, \\ Takatsuki City, Osaka 569, Japan
}

\begin{abstract}
Double-barreled potassium or chloride ion-selective microelectrodes were constructed using a liquid ion exchanger. Technical details of the fabrication of double-barreled microelectrodes, having a PD sensor as one barrel and an ionic sensor as the other, are described.

The sensitivity of $\mathrm{K}^{+}$or $\mathrm{Cl}^{-}$ion-selective microelectrodes exhibited an approximately Nernstian response over a temperature range of $7^{\circ}-$ $37^{\circ} \mathrm{C}$, and the electromotive force (EMF) was stable within $\pm 1 \mathrm{mV}$ for a few hours. The rise time was less than $1 \mathrm{sec}$. The effect of $\mathrm{pH}$ on the electrode response was negligible over a physiological range of $\mathrm{pH}$ 5.6 to 7.8 . The selectivity constants of the $\mathrm{K}^{+}$microelectrode to other cations were 0.011 for $\mathrm{Na}^{+}, 0.200$ for $\mathrm{NH}_{4}^{+}$, and less than 0.002 and 0.001 for $\mathrm{Ca}^{++}$and $\mathrm{Mg}^{++}$, respectively, while that of the $\mathrm{Cl}^{-}$microelectrode was 0.067 for $\mathrm{HCO}_{3}^{-}$. Glucose or urea has no effect on the EMF. Protein has a significant effect on ion exchanger membrane only when the concentration of the tested ion is low and protein is high.

On the basis of this background the determination of $\mathrm{K}^{+}$and $\mathrm{Cl}^{-}$activity was carried out both in vivo and in vitro on several biological samples, such as serum, tissue and cellular fluids, and other protein-containing fluids. The values obtained with the microelectrode were consistent with those obtained with the other conventional methods or with the current theory on electrolyte solutions.

These results were taken to assure the practical application of these electrodes to biological studies in many fields.
\end{abstract}

The electrolyte concentrations in biological fluid can be determined in several ways, such as flame-photometry for $\mathrm{Na}^{+}$and $\mathrm{K}^{+}$, atomic absorption spectrometry for $\mathrm{Ca}^{++}$and $\mathrm{Mg}^{++}$, spectrophotometry for $\mathrm{NH}_{4}^{+}$, electrometrical titration for $\mathrm{Cl}^{-}$, and so forth. The values obtained with these methods do not usually give

Received for publication July 16, 1976

藤本 守, 窪田隆裕 
the ionic activity, but only the total chemical concentration. Since the actual biological phenomena in the living organism are closely related to changes in ionic activity, what really has to be known for physiological studies is the ionic activity rather than the total concentration. Measurement of the ionic activity in biological fluids has been made possible by cation-sensitive glass electrodes for $\mathrm{H}^{+}$and $\mathrm{Na}^{+}$, and by ion-selective liquid ion exchanger electrodes for $\mathrm{K}^{+}, \mathrm{Cl}^{-}$, and $\mathrm{Ca}^{++}$ (EISENMAN, 1967). However, the presently available ion-selective (or ion-sensitive) electrodes are usually too large to measure the ionic activity in a small amount of sample or of fluids in a minute environment, such as intracellular space. The in vivo estimation of intracellular ionic activity can only be achieved by miniaturization of the ion-sensitive tip of the electrode.

WALKER (1971) described a method of manufacturing an ion-selective microelectrode with a single-barreled structure. KHURI and his associates (1972, 1974a, 1974b), VysKocIL and KRIZ (1972), and ZEUTHEN and his associates (1974) succeeded in manufacturing double-barreled ion-selective microelectrodes to measure, simultaneously, both the electrical potential difference (PD) across the cell membrane and selective local ionic activity of the cytoplasm. However, the descriptions of the method of fabrication and basic information on the physicochemical properties of these particular double-barreled microelectrodes are still insufficient. There are, in fact, several technical problems that might encounter in the miniaturization and practical use of such microelectrodes. There have also been reports of some substances causing interference in the liquid ion exchanger electrode (WALKER, 1971). Thus, there are still many problems to solve in the use of such electrodes in the measurement of intracellular ionic activity.

This paper discusses these problems and describes details of the method of manufacturing liquid ion exchanger microelectrodes, especially double barreled $\mathrm{K}^{+}$or $\mathrm{Cl}^{-}$ion-selective microelectrodes, and examines their biological applicability.

\section{METHODS}

Method of electrode fabrication. Thin-walled Pyrex glass capillaries with a 1.0 to $1.1 \mathrm{~mm}$ outside diameter were used. They were immersed in chromic acid and rinsed repeatedly with redistilled water before use. Two capillaries were mounted in parallel on a horizontal micropipet puller (Narishige PD-5). They were heated with a platinum ribbon over $5 \mathrm{~mm}$ in width and gently rotated $180^{\circ}$ along its longitudinal axis, and pulled in two changeable steps until the tip diameter was less than one micron. The length of the shank was about $1 \mathrm{~cm}$. One technical problem to be solved was that one limb of the double-barreled tip must be hydrophobic so that the organophilic liquid ion exchanger can remain in place along the limited length of the tip, while the other limb must be kept hydrophilic so that the aqueous internal solution can easily flow down to the tip. In the following, the two limbs are hereafter designated as tube $\mathrm{A}$ and tube $\mathrm{B}$, for the 
PD sensor and the ionic sensor, respectively. The above technique involves the following procedures:

(1) Pure acetone or $50 \%$ ethyl alcohol aqueous solution is manually injected into the open end of the tube A stem far down into the tip using an injection needle connected to a syringe. The needle is $10 \mathrm{~cm}$ long, $0.2 \mathrm{~mm}$ in diameter, and the tip had been electrolytically sharpened. To facilitate filling, a coaxial fiber-built-in glass capillary is preferably used for tube A. The other end of the glass capillary stem of tube A may be optionally closed by thermal fusion over a microflame. This serves to protect the tube A from contamination with silicone vapor when the electrode is baked in step (3).

(2) The entire tip is dipped for several seconds into a fresh solution of $0.3 \%$ silicone oil KF-96 (Shinyetsu Chemical Industry Co.) diluted with trichlorethylene. Microscopic examination is necessary to insure that tube B is sure of partially filled with the silicone solution to as much as 100 to $300 \mu$ to the very tip and that tube $A$ is completely filled with acetone. The other end of the tube B stem may be closed by thermal fusion to minimize further siliconization toward the shank.

(3) The electrode is then baked on a hot plate at $300^{\circ} \mathrm{C}$ for 15 to $30 \mathrm{~min}$. After cooling, the closed stem ends of tubes A and B are cut. Now, the assembly is ready for the immersion of the entire tip into the ion exchanger solution for filling. To facilitate filling, moderate suction is usually applied to the tube B. The commercial ion exchangers used were Corning $\# 477317$ for $\mathrm{K}^{+}$and $\# 477315$ for $\mathrm{Cl}^{-}$.

(4) Tube A as the PD sensor is filled with an internal reference solution from the open end of the stem far down to the tip with a fine needle. For $\mathrm{K}^{+}$ionselective microelectrodes, this reference solution must be $\mathrm{K}^{+}$-free to avoid interference with the sensitivity of the ionic sensor due to local diffusion of $\mathrm{K}^{+}$from the tip. In the case of extracellular $\mathrm{K}^{+}$determinations, $\mathrm{K}^{+}$-free Ringer solution was used as the internal solution, and for intracellular $\mathrm{K}^{+}$determinations, $1 \mathrm{M}$ $\mathrm{NaCl}$ was used. For $\mathrm{Cl}^{-}$ion-selective microelectrodes, the internal solution was $10 \mathrm{~mm} \mathrm{NaCl}$ dissolved in $1 \mathrm{M}$ sodium formate for both intra- and extracellular use. The internal reference solution for tube $\mathrm{B}$ for the ionic sensor was $0.5 \mathrm{M} \mathrm{KCl}$ solution, and it could be injected through the stem. Air bubbles could be removed by manual tapping or by inserting a thin metal wire while observing the tip under a dissecting microscope. Minute air bubbles of less than $100 \mu$ in length may be disregarded as they will disappear from solution within an hour.

The fabricated microelectrodes were then stored vertically with their tips down in $0.5 \mathrm{M} \mathrm{KCl}$ solution in a moist-chamber until use. Major difficulties sometimes encountered with the microelectrodes were a) formation of a silicone plug in the tip of tube $\mathrm{B}, \mathrm{b}$ ) a bridge formation or cross coupling of the ion exchanger across both tube at the tips, c) extremely high electrical resistance in tube B, d) loss of ion exchanger within a few hours, and e) tiny cracks in the tip. Technical 
improvements could be achieved, however, by changing the tapering of the microelectrode, changing the silicone dilution, microgrinding of the tip, and mechanical reinforcement of the twisted part of the microelectrode with dental wax.

Test for electrode characterization. Determination of the selectivity constant of an ion-selective microelectrode, $K_{\mathrm{ij}}$, was carried out by use of the following formula:

$$
K_{\mathrm{ij}}=10^{\left(E_{\mathrm{j}} / \alpha_{\mathrm{j}}-E_{\mathrm{i}} / \alpha_{\mathrm{i}}\right)}
$$

where $E_{\mathrm{i}}$ and $E_{\mathrm{j}}$ are the electromotive forces (EMF) of an ion-selective microelectrode at any given common value of the ionic activity for the ionic species $i$ and $\mathrm{j}$; and $\alpha_{\mathrm{i}}$ and $\alpha_{\mathrm{j}}$ are the slope constants of the ionic species $\mathrm{i}$ and $\mathrm{j}$, respectively. $E_{\mathrm{i}}$ and $\alpha_{\mathrm{i}}$ were determined with a standard solution containing the ionic species $\mathrm{i}$ but not $\mathrm{j}$, whereas $E_{\mathrm{j}}$ and $\alpha_{\mathrm{j}}$ were determined with a standard solution containing the ionic species $\mathrm{j}$ but not $\mathrm{i}$.

The intracellular activity of the ionic species $i$ was obtained by the following equation (derived from WALKER, 1971):

$$
a_{\mathrm{i}_{\mathrm{ICF}}}=\left(a_{\mathrm{i}_{\mathrm{ECF}}}+K_{\mathrm{ij}_{\mathrm{j}}} a_{\mathrm{j}_{\mathrm{ECF}}}\right) 10^{\left(E_{\mathrm{T}}-E_{\mathrm{Mem}}\right) / \alpha_{\mathrm{i}}}-K_{\mathrm{ij}} a_{\mathrm{j}_{\mathrm{ICF}}}
$$

where $a_{\mathrm{i}}$ and $a_{\mathrm{j}}$ are the activities of the ionic species $\mathrm{i}$ and $\mathrm{j}$; suffix ICF and ECF represent the intracellular fluid and extracellular fluid; and $E_{\mathrm{T}}$ and $E_{\mathrm{Mem}}$ denote EMF of one barrel used for the ionic sensor and that for the PD sensor, respectively. The activity of the ionic species within the cell can be assesed by measuring $E_{\mathrm{T}}$ and $E_{\mathrm{Mem}}$ and adapting reasonable values of $a_{\mathrm{i}_{\mathrm{ECF}}}, a_{\mathrm{j}_{\mathrm{ECF}}}$, and $a_{\mathrm{j}_{\mathrm{ICF}}}$ for the above equation with an assumption that $K_{\mathrm{ij}}$ and $\alpha_{\mathrm{i}}$ have been known and remained constant. When $K_{\mathrm{ij}}$ is sufficiently small and $a_{\mathrm{j}_{\mathrm{ICF}}}$ is also small in itself, the term involving the latter can be neglected.

The electrometry was made with a differential electrometer (Keithley 604) by connecting the electrode terminals through $\mathrm{Ag}-\mathrm{AgCl}$ wires. Both digital and analog voltage outputs were displayed with digital multimeters (Keithley 160) and a dual channel recorder (Rika-Denki B-381). The output of the reference barrel was connected to ground. The electrical resistance was measured with a digital electrometer (Keithley 616).

The activity coefficient of standard ionic solution was calculated from the modified Debye-Hückel formula (ROBINSON and STOKES, 1970):

$$
\begin{aligned}
& -\log \gamma=\frac{A \sqrt{I}}{1+\stackrel{\mathrm{a}}{ } B \sqrt{I}}-0.055 I \\
& I=\frac{1}{2} \sum c_{\mathrm{i}} z_{\mathrm{i}}^{2}
\end{aligned}
$$

where, $\gamma$ is the activity coefficient; $A$ and $B$ are the Debye constants dependent upon temperature, dielectric constant of solvent and ionic size of solute; $a$ is the ion size parameter: e.g., 3.0 for $\mathrm{K}^{+}, \mathrm{Cl}^{-}$and 4.5 for $\mathrm{Na}^{+}$(BATES, 1964); $I$ is the 
ionic strength; $c_{1}$ is the molar concentration of the ith ion; and $z_{\mathrm{i}}$ is valence of the ith ion. In the examination of the temperature effect on the EMF slope, the figures shown in Table 1 were used for $\mathrm{KCl}$ standard solutions. The slope con-

Table 1. Activity coefficient of $\mathrm{KCl}$ solution.

(I) Activity coefficient $\gamma$ :

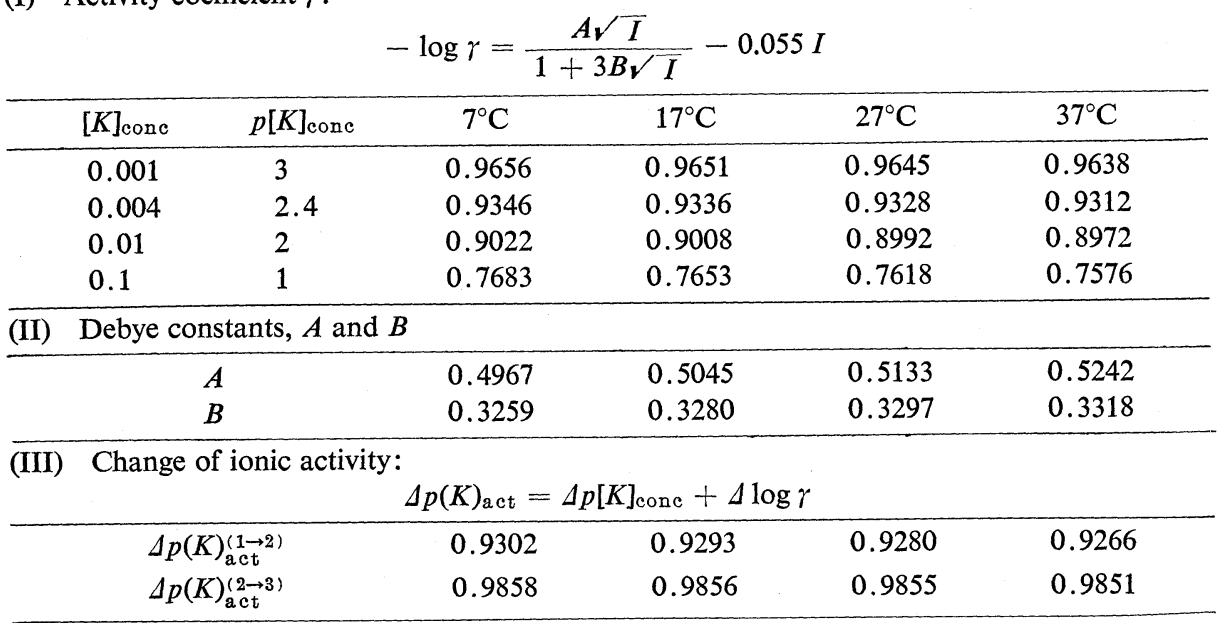

$p(K)_{\text {act }}$ means the negative logarithm of $K^{+}$activity, and $p[K]_{\text {conc }}$ is that of $\mathrm{K}^{+}$concentration. $(1 \rightarrow 2)$ indicates the range of $p[K]_{\text {conc }}$ of 1 to 2 , where the change of $p(K)_{\text {act }}$ is calculated, and similarly $(2 \rightarrow 3)$ indicates the $p[K]_{\text {conc }}$ range of 2 to 3 .

stant, $\alpha$, was calibrated by activities of two given standard solutions, as follows:

$$
\alpha=\Delta E /\{\Delta p[X]+\Delta \log \gamma\}
$$

where, $[X]$ stands for the concentration of the ionic species.

Buffer solutions were made with mixtures of $10 \mathrm{mEq} / 1$ sodium in the form of acid phosphate (A solution) and alkali phosphate (B solution), both containing $4 \mathrm{mM} \mathrm{KCl}$. The two solutions, $\mathrm{A}$ and $\mathrm{B}$, were mixed in the following ratios: $\mathrm{A} / \mathrm{B}=9.5 / 0.5(\mathrm{pH} \mathrm{5.68)} ; 7 / 3(\mathrm{pH} \mathrm{6.60)} ; 3 / 7(\mathrm{pH} 7.18)$; and 0.5/9.5 (pH 7.78). The $\mathrm{pH}$ values were checked with a Beckman expandomatic $\mathrm{pH}$ meter.

Biological samples used for this study were human serum furnished by the Central Laboratory of Osaka Medical College Hospital, frog serum (Rana catesbeiana), and bovine serum albumin (Sigma Chemical Co., Fraction V). The total concentration of $\mathrm{Na}^{+}$and $\mathrm{K}^{+}$was determined with a Coleman flame photometer and $\mathrm{Cl}^{-}$with a Cotlove titrator (Buchler Instruments, Inc.). The renal micropuncture study was done on urethane-anaesthetized male bullfrogs (Rana catesbeiana). The details of the experimental procedure was described elsewhere (Fujimoto et al., 1977). 


\section{RESULTS}

Electrode response to various ions

Figure 1 shows an example of the EMF of a $\mathrm{K}^{+}$ion-selective microelectrode in solutions containing various ionic concentrations of electrolytes at $25^{\circ} \mathrm{C}$. The electrode responded not only to $\mathrm{K}^{+}$but also to other monovalent cations (e.g., $\mathrm{NH}_{4}^{+}$and $\mathrm{Na}^{+}$) and to divalent cations (e.g., $\mathrm{Ca}^{++}$and $\mathrm{Mg}^{++}$). A linear response

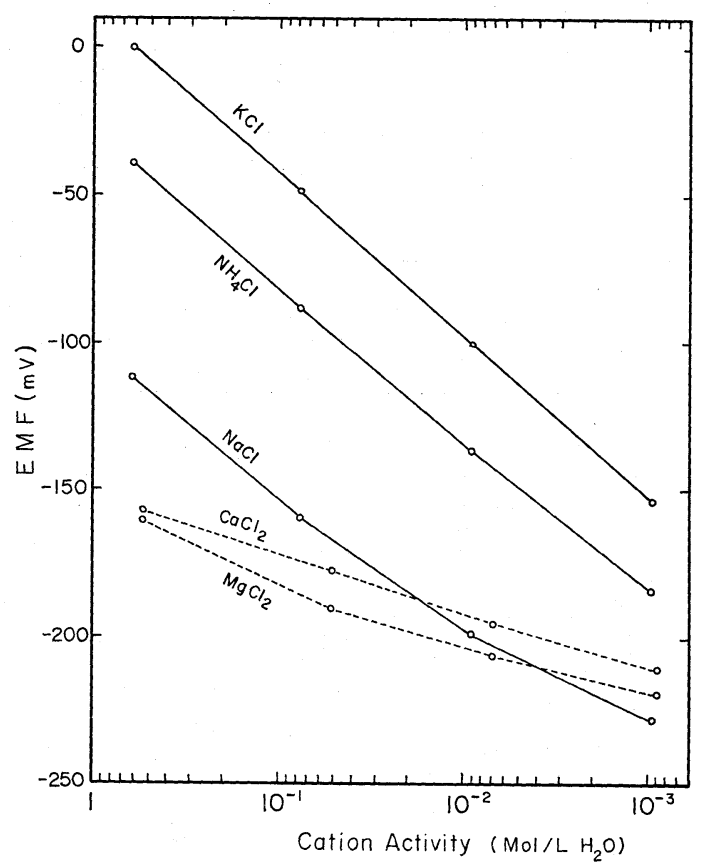

Fig. 1. EMF vs. ionic activity plots for various cations obtained with double-barreled $\mathrm{K}^{+}$ ion-selective microelectrodes at $25^{\circ} \mathrm{C}$. Electrode response is nearly theoretical. Selectivity constants of various cations with respect to potassium can be calculated from this figure.

was observed for $\mathrm{KCl}$ and $\mathrm{NH}_{4} \mathrm{Cl}$ solutions over a test range of $10^{-3}$ to $1 \mathrm{M}$, and for $\mathrm{NaCl}$ solutions over a range of $10^{-2}$ to $1 \mathrm{M}$. The horizontal distance between any two curves represents the selectivity of those two. For instance, at an EMF of $-100 \mathrm{mV}$, the activity ratio of $\mathrm{NH}_{4}^{+} / \mathrm{K}^{+}$is shown to be $5 / 1$. Namely, this particular $\mathrm{K}^{+}$ion-selective microelectrode has a selectivity for $\mathrm{K}^{+}$over $\mathrm{NH}_{4}^{+}$by a factor of 5: in other words, the selectivity ratio $\left(\mathrm{K}^{+} / \mathrm{NH}_{4}^{+}\right)$is 5 , or the selectivity constant, $K_{\mathrm{K} \mathrm{NH}_{4}}$ is 0.200 . As to the selectivity of $\mathrm{Na}^{+}$to $\mathrm{K}^{+}$at an EMF of -150 $\mathrm{mV}, \mathrm{K}^{+} / \mathrm{Na}^{+}$was found to be $102 / 1$, or $K_{\mathrm{K} \mathrm{Na}}$ is 0.0098 . The slope for $\mathrm{KCl}$, given in Fig. 1, represents $55 \mathrm{mV} / \mathrm{p}(\mathrm{K})$, which is fairly close to the theoretical value, $59 \mathrm{mV}$ at $25^{\circ} \mathrm{C}$. The slopes of the divalent cations, $\mathrm{Ca}^{++}$and $\mathrm{Mg}^{++}$, as seen in Fig. 1, are about half those of the monovalent cations. This is because 
the results in Fig. 1 are expressed on a molar basis not on an equivalent basis.

The $\mathrm{K}^{+}$selectivity to divalent cations, $\mathrm{Ca}^{++}$or $\mathrm{Mg}^{++}$was more than 1000 , as estimated at an EMF of $-150 \mathrm{mV}$ (i.e., $K_{\mathrm{K} \mathrm{Ca}}<0.001$ and $K_{\mathrm{K} \mathrm{Mg}}<0.00099$ ). Consistently higher voltages were obtained with the $\mathrm{KCl}$ standard series than with other cationic series tested, indicating that this electrode had the highest response to $\mathrm{K}^{+}$ion among the alkali metal ions on a molar basis.

The slope obtained with 12 different $\mathrm{K}^{+}$ion-selective microelectrodes are shown in Table 2. They were determined individually in different concentration ranges of $\mathrm{KCl}$ standard at $25^{\circ} \mathrm{C}$. Though the mean slopes determined in a dilute range seemed lower, no significant difference was observed between them and those at more concentrated ranges. The average value was calculated to be $54.8 \pm$ 2.2 (S.D.) $\mathrm{mV} / \mathrm{p}(\mathrm{K})$. The ratio of the measured slope to the Nernstian slope was 0.93 with our $\mathrm{K}^{+}$ion-selective microelectrodes. Using a standard range of 1$10 \mathrm{mEq} / 1 \mathrm{KCl}$, the $K$ concentration of the test solution containing $4.00 \mathrm{mEq} / 1$ was determined with the electrodes. In Table 2 the data show an average of $4.00 \pm 0.04$ (S.D.) $\mathrm{mEq} / 1$ and a coefficient of variation of $1 \%$.

Table 2. Slope constants of double-barreled $\mathrm{K}^{+}$ion-selective microelectrodes in $\mathrm{KCl}$ standard solution at $25^{\circ} \mathrm{C}$.

\begin{tabular}{rccccc}
\hline \multirow{2}{*}{ No. } & \multicolumn{2}{c}{ Concentration range of standard solution } & & Average & $\begin{array}{c}\text { Test solution } \\
4.0 \mathrm{mEq} / 1\end{array}$ \\
\cline { 2 - 4 } & $1-10 \mathrm{mM}$ & $10-100 \mathrm{mM}$ & $100-1,000 \mathrm{mM}$ & & 51.5 \\
\hline 1 & 51.6 & 51.1 & 51.8 & 501 \\
2 & 51.1 & 50.1 & 51.0 & 55.7 & 3.95 \\
3 & 55.7 & 55.7 & 55.9 & 5.03 \\
4 & 53.7 & 53.6 & 57.1 & 54.8 & 4.07 \\
5 & 54.2 & 52.5 & 58.3 & 55.0 & 3.97 \\
6 & 52.1 & 55.7 & 57.1 & 55.0 & 3.97 \\
7 & 52.6 & 54.1 & 58.3 & 55.0 & 4.05 \\
8 & 55.2 & 56.8 & 58.9 & 57.0 & 3.92 \\
9 & 50.6 & 52.6 & 54.7 & 52.6 & 4.01 \\
10 & 56.7 & 56.3 & 58.9 & 57.3 & 4.00 \\
11 & 54.7 & 56.8 & 57.9 & 56.5 & 4.02 \\
12 & 55.7 & 56.8 & 57.7 & 56.7 & 4.05 \\
Mean & 53.7 & 54.3 & 56.5 & & \\
\pm S.D. & 2.0 & 2.4 & 2.7 & 54.8 & 4.00 \\
\hline
\end{tabular}

Figure 2 gives the EMF of a $\mathrm{Cl}^{-}$ion-selective microelectrode in test solutions containing $\mathrm{Cl}^{-}, \mathrm{HCO}_{3}^{-}, \mathrm{SO}_{4}^{--}, \mathrm{H}_{2} \mathrm{PO}_{4}^{-}$, or $\mathrm{HPO}_{4}^{--}$at various concentrations at $25^{\circ} \mathrm{C}$. Unlike the cation-selective microelectrode, a more negative EMF was observed with increasing concentration of anions. The slope for $\mathrm{Cl}^{-}$obtained from the calibrated line was $50 \mathrm{mV} / \mathrm{p}(\mathrm{Cl})$, which could be used in practical experiments. The selectivity between $\mathrm{Cl}^{-}$and $\mathrm{HCO}_{3}^{-}$, as estimated at an EMF of $100 \mathrm{mV}$, was calculated to be $\mathrm{Cl}^{-} / \mathrm{HCO}_{3}^{-}=12 / 1$ or $K_{\mathrm{Cl} \mathrm{HCO}_{3}}=0.083$. The divalent 


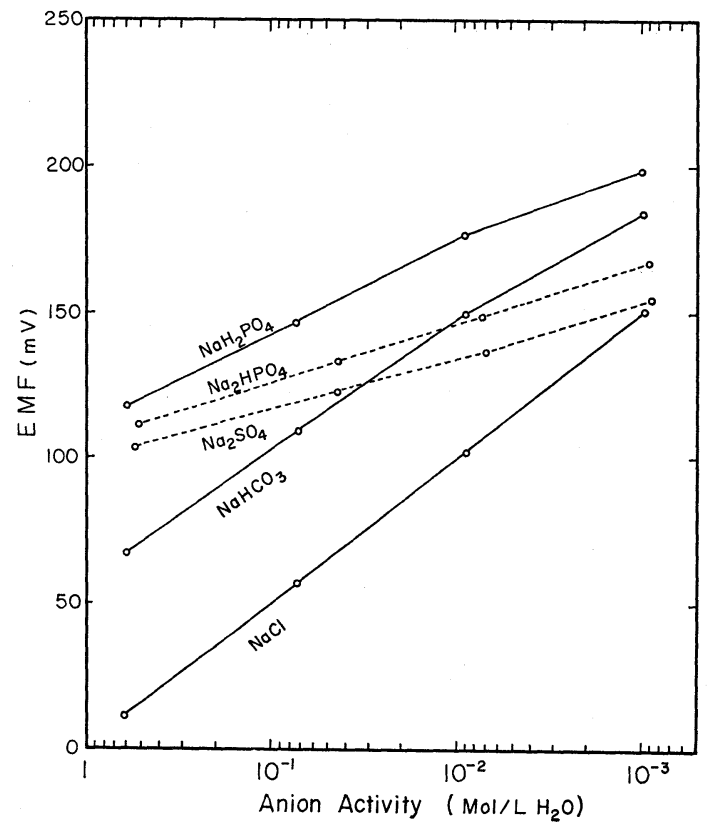

Fig. 2. EMF vs. ionic activity plots for various anions obtained with double-barreled $\mathrm{Cl}^{-}$ ion-selective microelectrodes at $25^{\circ} \mathrm{C}$. The slope constants of the lines are nearly theoretical. Selectivity constants of various anions with respect to chloride can also be obtained from this figure.

anions, $\mathrm{SO}_{4}^{--}$and $\mathrm{HPO}_{4}^{--}$have slopes of about half those of the monovalent anions. As can be inferred from Fig. 2, measurement of $\mathrm{Cl}^{-}$activity may be difficult in an environment containing less than $5 \mathrm{mEq} / 1$ of $\mathrm{Cl}^{-}$because under such a circumstance interference of other coexistent anions is increased. However, since the measured intracellular $\mathrm{Cl}^{-}$activity is usually in the order of 10 $\mathrm{mEq} / 1$ (Fujmoto et al., 1977), it is possible that contributions of intracellular $\mathrm{HCO}_{3}^{-}$and other anions to the EMF of the $\mathrm{Cl}^{-}$microelectrode are reduced to less than $9 \%$ of $\mathrm{Cl}^{-}$selectivity. Therefore, it is feasible that measurements of intracellular $\mathrm{Cl}^{-}$activity can be carried out with reasonable accuracy.

Table 3 gives the data of slopes of the $\mathrm{Cl}^{-}$ion-selective microelectrode at different concentration ranges. Within a test range from $10^{-3}$ to $10^{-1} \mathrm{M}$ (even to $1 \mathrm{M}$ ), it remained essentially constant, and its average in a range of $10^{-3}-1 \mathrm{M} \mathrm{NaCl}$ solution was $53.1 \pm 2.0$ (S.D.) $\mathrm{mV}$ for tenfold change in $\mathrm{Cl}^{-}$activity. Further, individual electrodes gave fair readings with the test solution containing $110 \mathrm{~mm}$ $\mathrm{Cl}^{-}$with a coefficient of variation of approximately $2 \%$, as indicated in the table.

Detailed analyses of the selectivity constant were performed with special reference to the selectivity ratio of $\mathrm{K}^{+} / \mathrm{Na}^{+}$for the $\mathrm{K}^{+}$microelectrode and $\mathrm{Cl}^{-} /$ $\mathrm{HCO}_{3}^{-}$for the $\mathrm{Cl}^{-}$microelectrode because of their physiological importance, the 
Table 3. Slope constants of double-barreled $\mathrm{Cl}^{-}$. ion-selective microelectrodes in $\mathrm{KCl}$ standard solution at $25^{\circ} \mathrm{C}$.

\begin{tabular}{cccccc}
\hline \multirow{2}{*}{ No. } & \multicolumn{2}{c}{ Concentration range of standard solution } & Average & $\begin{array}{c}\text { Test solution } \\
110 \mathrm{mEq} / 1\end{array}$ \\
\cline { 2 - 4 } & $1-10 \mathrm{mM}$ & $10-100 \mathrm{mM}$ & $100-1,000 \mathrm{mM}$ & & 111.3 \\
\hline 1 & 49.6 & 50.7 & 53.7 & 51.4 & - \\
2 & 54.8 & 49.6 & 48.5 & 51.0 & 110.4 \\
3 & 52.0 & 52.3 & 54.5 & 52.9 & 113.1 \\
4 & 51.0 & 51.0 & 53.3 & 51.8 & 111.6 \\
5 & 54.8 & 54.0 & 53.7 & 54.2 & 109.9 \\
6 & 54.8 & 54.5 & 56.7 & 55.3 & 106.6 \\
7 & 51.7 & 55.1 & 56.1 & 54.3 & -109.4 \\
8 & 51.7 & 52.9 & 53.7 & 53.4 & 111.2 \\
9 & 48.6 & 51.8 & 53.7 & 51.4 & -114.5 \\
10 & 53.8 & 52.9 & 53.7 & 53.5 & 110.3 \\
11 & 55.9 & 58.7 & 59.7 & 58.1 & 110.8 \\
12 & 54.8 & 52.7 & 49.5 & 52.3 & 2.1 \\
13 & 52.8 & 49.6 & 51.3 & 51.2 & \\
Mean & 52.8 & 52.8 & 53.7 & 53.1 & \\
\pm S.D. & 2.3 & 2.5 & 2.9 & 2.0 &
\end{tabular}

Table 4. Slope and selectivity constants.

\begin{tabular}{|c|c|c|c|}
\hline \multicolumn{4}{|c|}{ Double-barreled $\mathrm{K}^{+}$ion-selective microelectrodes } \\
\hline No. & Slope & $\mathrm{K}^{+} / \mathrm{Na}^{+}$ & $K_{\mathrm{K} \mathrm{Na}}\left(10^{-4}\right)$ \\
\hline 1 & 55.7 & 78 & 128 \\
\hline 2 & 52.1 & 110 & 91 \\
\hline 3 & 53.7 & 88 & 114 \\
\hline 4 & 54.7 & 88 & 114 \\
\hline 5 & 54.7 & 97 & 103 \\
\hline 6 & 56.7 & 102 & 98 \\
\hline 7 & 55.7 & 100 & 100 \\
\hline 8 & 55.7 & 96 & 104 \\
\hline 9 & 56.7 & 100 & 100 \\
\hline Mean & 55.1 & 95.4 & 106 \\
\hline \pm S.D. & 1.5 & 9.4 & 10 \\
\hline \multicolumn{4}{|c|}{ Double-barreled $\mathrm{Cl}^{-}$ion-selective microelectrodes } \\
\hline No. & Slope & $\mathrm{Cl}^{-} / \mathrm{HCO}_{3}^{-}$ & $K_{\mathrm{C} 1 \mathrm{HCO}_{3}}\left(10^{-4}\right)$ \\
\hline 1 & 50.1 & 11 & 909 \\
\hline 2 & 55.1 & 20 & 500 \\
\hline 3 & 45.6 & 20 & 500 \\
\hline 4 & 53.7 & 14 & 714 \\
\hline 5 & 50.6 & 17 & 588 \\
\hline 6 & 49.6 & 12 & 833 \\
\hline Mean & 50.8 & 15.7 & 674 \\
\hline \pm S.D. & 3.1 & 3.6 & 158 \\
\hline
\end{tabular}


data being listed in Table 4 . The average selectivity ratio derived from 9 different $\mathrm{K}^{+}$ion-selective microelectrodes for $\mathrm{K}^{+} / \mathrm{Na}^{+}$was calculated to be $95.4 \pm 9.4$ (S.D.) (the upper half of Table 4). The $\mathrm{Cl}^{-}$microelectrode had an average selectivity ratio of $15.7 \pm 3.6$ (S.D.) for $\mathrm{HCO}_{3}^{-}$(6 different electrodes, the lower half of Table 4).

\section{Response time, stability and aging of microelectrode}

The response time of the electrode is theoretically defined as the period beginning with the dipping of the tip into a new solution to the time when the EMF comes to more than $95 \%$ of complete equilibrium. However, in practice one can only estimate the rise time (FERRIS, 1974), or the time required for the output response to rise from $10 \%$ to $90 \%$ of net change toward the final value for an applied step input. It usually averaged less than $1 \mathrm{sec}$, ranging from 0.2 to 3 sec. The less the electrode resistance of the ionic barrel, the shorter is the response time. Table 5 shows the data for the $\mathrm{Cl}^{-}$ion-selective microelectrodes. It appeared that the electrical resistance of the ionic barrel showed a significant relationship to the length of the ion exchanger column mounted at the tip. When the electrode resistance was high, it seemed to interfere with reactivity to test

Table 5. Electrical resistance and response time of double-barreled $\mathrm{Cl}^{-}$ion-selective microelectrodes.

\begin{tabular}{lccc}
\hline Length of exchanger at $\operatorname{tip}(\mu)$ & $50-200$ & $250-1,000$ & $1,000-4,000$ \\
\hline Electrical resistance $\left(\times 10^{9} \Omega\right)$ & $2.1-3.4$ & $4.7-5.2$ & $8.1<$ \\
\hline Slope $(\mathrm{mV} / \mathrm{p}(\mathrm{Cl}))$ & $35-55$ & $20-42$ & $10-23$ \\
\hline Rise time $(\mathrm{sec})$ & $<1$ & $1-60$ & $45-180$ \\
\hline
\end{tabular}

substances. The electrical resistance in most of the ionic barrel was not more than a few multiples of $10^{9} \Omega$. The shift of electrode output was less than $1 \mathrm{mV}$ for one hour. The $\mathrm{Cl}^{-}$ion-selective microelectrode was usually more labile than the $\mathrm{K}^{+}$ion-selective microelectrode. The electrodes were usually found to age in one or two days, although some were useful even after a week. To retard aging, the electrodes should be kept in $\mathrm{KCl}$ solution of the same concentration as in the internal reference solution in the ionic barrel of the microelectrode.

\section{Temperature effect}

To analyse the temperature effect on liquid ion exchanger microelectrodes, measurements of both EMF and slope constant ( $\alpha$ of microelectrode, see METHODS for details) to the test ion were made on a $\mathrm{K}^{+}$or $\mathrm{Cl}^{-}$ion-selective microelectrode at different temperatures $\left(7^{\circ}, 17^{\circ}, 27^{\circ}\right.$, and $\left.37^{\circ} \mathrm{C}\right)$. The EMF data are shown in Fig. 3. The vertical distance of two dots at a given temperature indicates the size of the apparent slope constant to the relevant ion of that particular microelectrode in the concentration range indicated. It is evident that the slope constant $(\alpha)$ of 


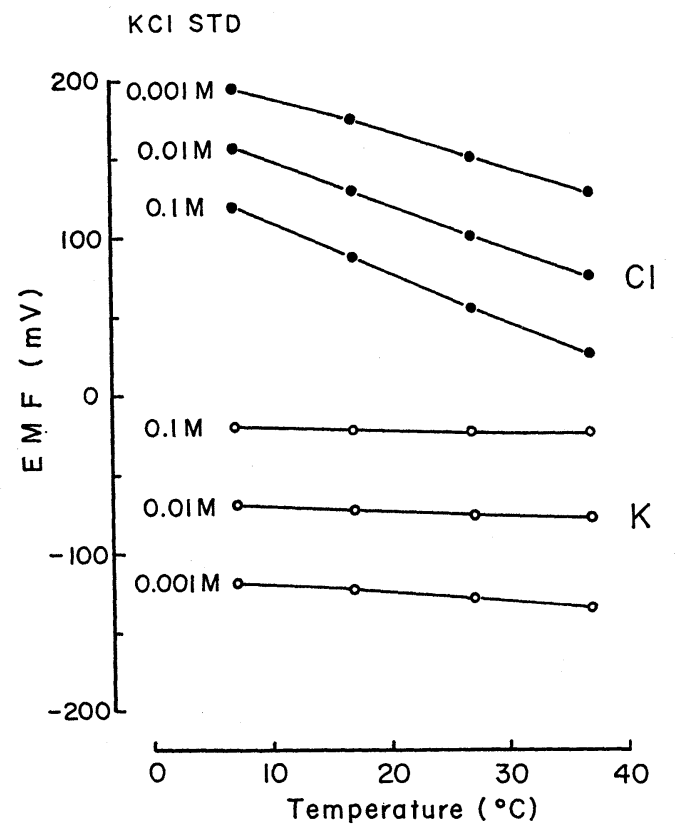

Fig. 3. Effect of temperature on the EMF of double-barreled $\mathrm{K}^{+}$or $\mathrm{Cl}^{-}$ion-selective microelectrodes. The response curves of the $\mathrm{Cl}^{-}$electrode are shown in the upper half and those of $\mathrm{K}^{+}$electrode in the lower half.

the microelectrode output increases with temperature. Temperature was found to have a profound effect on the EMF of the $\mathrm{Cl}^{-}$microelectrode. Hence, the $\mathrm{Cl}^{-}$microelectrode is more labile when compared with the $\mathrm{K}^{+}$microelectrode. Values of the slope constant of the microelectrode shown in Table 6 were calculated using ionic activities in Table 1. It is indicated the $n$ value (ratio of the

Table 6. Effect of temperature on double-barreled $\mathrm{K}^{+}$or $\mathrm{Cl}^{-}$ ion-selective microelectrodes.

\begin{tabular}{ccccc}
\hline Temperature $\left({ }^{\circ} \mathrm{C}\right)$ & 7 & 17 & 27 & 37 \\
\hline Nernstian slope $(\mathrm{mV} / \mathrm{p}(\mathrm{X}))$ & 55.5 & 57.5 & 59.5 & 61.5 \\
\hline $\begin{array}{c}\text { Measured slope for } \mathrm{K}^{+} \\
(\text {mean } \pm \text { S.D. })\end{array}$ & $\begin{array}{c}49.2 \pm 3.7 \\
n_{\mathrm{K}}\end{array}$ & $\begin{array}{c}51.8 \pm 3.4 \\
0.90\end{array}$ & $\begin{array}{c}53.9 \pm 2.4 \\
0.91\end{array}$ & $\begin{array}{c}56.6 \pm 1.6 \\
0.92\end{array}$ \\
$\begin{array}{c}\text { Reading of test solution } \\
(4 \mathrm{mM} \mathrm{K})\end{array}$ & - & $4.01 \pm 0.07$ & $4.03 \pm 0.07$ & $3.90 \pm 0.06$ \\
\hline $\begin{array}{c}\text { Measured slope for } \mathrm{Cl}^{-} \\
(\text {mean } \pm \text { S.D.) } \\
\quad n_{\mathrm{c} 1}\end{array}$ & $40.5 \pm 4.3$ & $45.8 \pm 2.4$ & $50.7 \pm 1.6$ & $55.0 \pm 1.2$ \\
$\begin{array}{c}\text { Reading of test solution } \\
(110 \mathrm{mM} \mathrm{Cl})\end{array}$ & 0.73 & 0.80 & 0.85 & 0.89 \\
\hline
\end{tabular}


measured slope to the Nernstian slope) increases almost linearly with temperature. The $n$ value represents a subideal behavior of the ion-selective microelectrode with respect to the Nernstian response. Since the ion-exchange properties are related to the oil-to-water partition coefficient of the ion and the association constant of the organic solute in the ion exchanger to the test ion, these factors are considered to be influenced by change of temperature. Confirmative tests on the estimation of ionic concentration were carried out using $4 \mathrm{mM} \mathrm{KCl}$ solution for the $\mathrm{K}^{+}$ionselective microelectrode and $110 \mathrm{mM} \mathrm{KCl}$ for the $\mathrm{Cl}^{-}$ion-selective microelectrode at different temperatures. The readings (ionic activities) obtained (Table 6) gave satisfactory results over the temperature range tested. These data suggest that as far as measurement is done at the same or at a constant temperature as in the calibrations, accurate results can be obtained.

pH effect

Figure 4 shows the effect of $\mathrm{pH}$ changes ranging from 5.68 to 7.78 on the estimation of the ionic activity in test solutions with $\mathrm{K}^{+}$and $\mathrm{Cl}^{-}$ion-selective microelectrodes using a sample series containing $4 \mathrm{mM} \mathrm{K}^{+}$and $100 \mathrm{mM} \mathrm{Cl}^{-}$. Figure 4

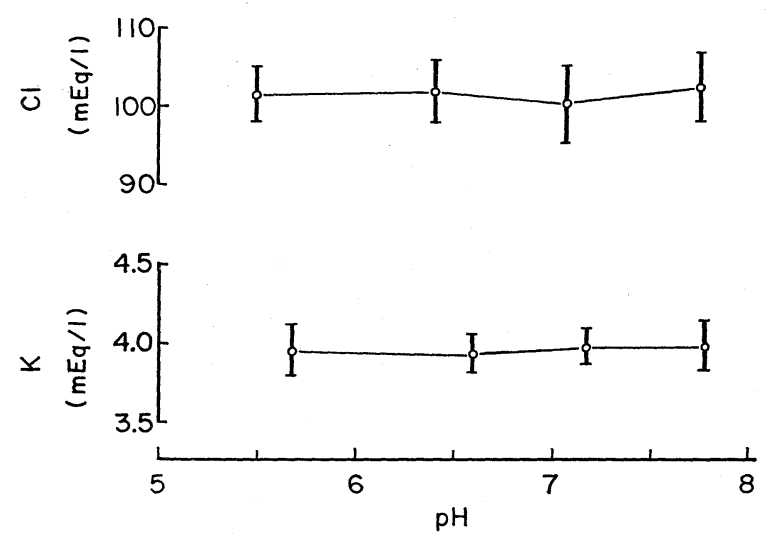

Fig. 4. Effect of $\mathrm{pH}$ on double-barreled $\mathrm{K}^{+}$or $\mathrm{Cl}^{-}$ion-selective microelectrodes. Open circle and vertical line through it give the mean \pm S.D. obtained with 5 different electrodes.

indicates that the effect of $\mathrm{pH}$ changes in the physiological range on the $\mathrm{K}^{+}$or $\mathrm{Cl}^{-}$ microelectrode is negligible. In a higher range of $\mathrm{K}^{+}$concentration, such as $100 \mathrm{mM}$, or a lower range of $\mathrm{Cl}^{-}$concentration, such as $10 \mathrm{~mm}$, the effect of $\mathrm{pH}$ changes on these microelectrodes also remained less than several $\%$ in coefficient of variation: namely, 2.8 to 4.1 (average 3.6$) \%$ in the $\mathrm{pH}$ range of 5.5 to 7.0 , and 3.1 to 6.0 (average 4.9 ) \% in the $\mathrm{pH}$ range of 7.0 to 7.8 , while that for the $\mathrm{Cl}^{-}$ microelectrode averaged $4.3(3.3-6.1) \%$ for the $\mathrm{pH}$ range of 5.7 to 7.8 . 


\section{Protein effect}

Purified bovine serum albumin was dissolved in a series of $\mathrm{KCl}$ standard solutions in different concentrations from $10^{-5}$ to $10^{-3} \mathrm{M}$. The EMF of the liquid ion exchanger microelectrodes responding to a protein-containing standard solution is shown for a $\mathrm{K}^{+}$ion-selective microelectrode in the lower curves in Fig. 5 and

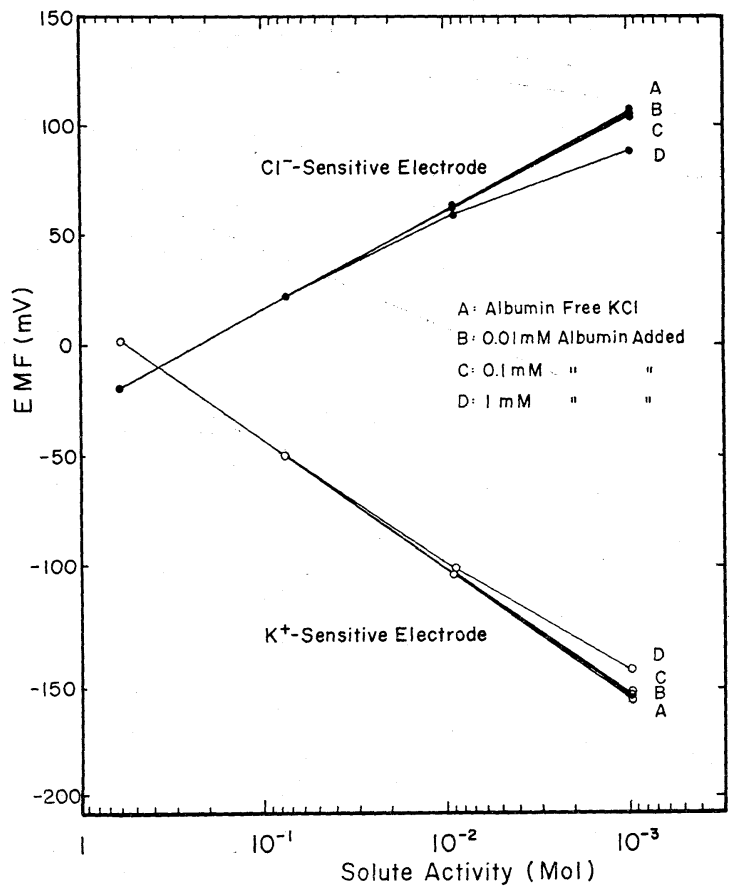

Fig. 5. EMF $v s$, ionic activity plots for $\mathrm{KCl}$ solutions containing various concentrations of albumin. Curve A: Response to albumin-free $\mathrm{KCl}$ solution. Curve $\mathrm{B}, \mathrm{C}$ and D represent those for $\mathrm{KCl}$ solutions containing $0.01,0.1$ and $1.0 \mathrm{~mm}$ albumin, respectively.

for a $\mathrm{Cl}^{-}$ion-selective microelectrode in the upper curves. In both cases, bovine serum albumin of 0 to $0.1 \mathrm{~mm}$ exerts little effect on the EMF independently of $\mathrm{K}^{+}$ concentrations, but $1 \mathrm{~mm}$ albumin produces an increasingly large deviation of the EMF from that in the $\mathrm{KCl}$ standard solution with progressive dilution.

\section{Effect of other substances}

Figure 6 shows the EMF of a $\mathrm{K}^{+}$ion-selective microelectrode (the lower half) and $\mathrm{Cl}^{-}$ion-selective microelectrode (the upper half) in response to various concentrations of standard $\mathrm{KCl}$ solutions, and solutions containing different concentrations of urea and glucose dissolved in redistilled water in which total salt concentration is less than $10^{-5} \mathrm{M}$. As is clearly shown, both urea and glucose have only a slight effect on responses of the ion exchanger microelectrode. This 
might be due to impurities in the test materials (glucose or urea in this study).

Application to biological samples

To confirm the applicability of the ion-selective micro-electrodes to biological samples, determinations of $\mathrm{K}^{+}$activity as well as $\mathrm{Cl}^{-}$activity were performed

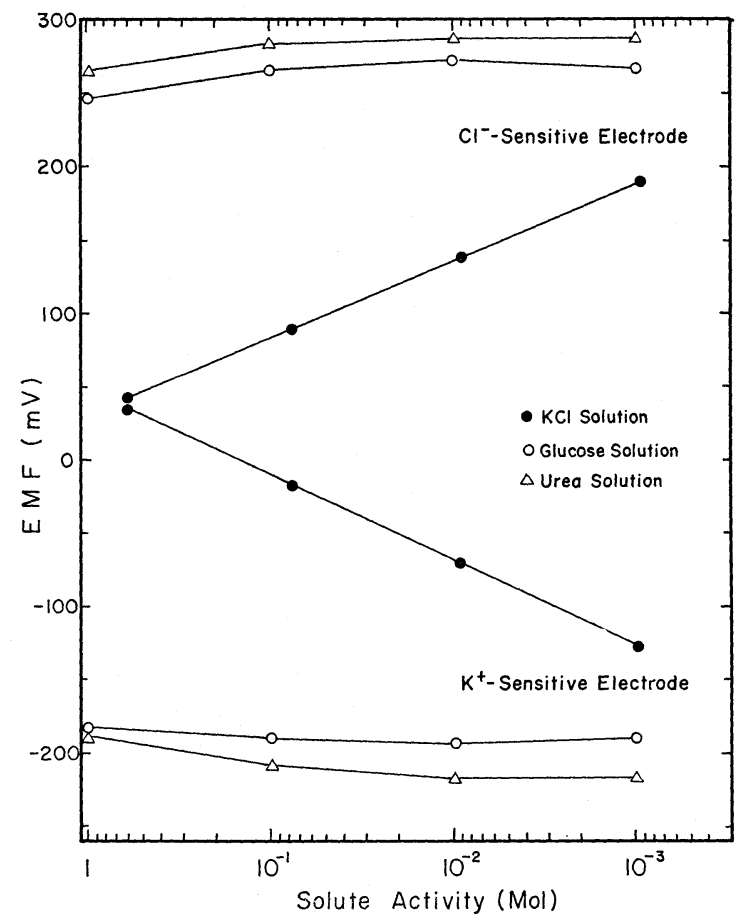

Fig. 6. Effect of glucose or urea on double-barreled $\mathrm{K}^{+}$of $\mathrm{Cl}^{-}$ion-selective microelectrodes. Closed circles $(\bullet)$ are EMF in $\mathrm{KCl}$ solution, open circles $(O)$ are those in $\mathrm{K}^{+}$-free glucose solutions, and open triangles $(\triangle)$ are those in $\mathrm{K}^{+}$-free urea solutions of different concentrations.

both in vitro and in vivo.

Table 7 shows the results of the $\mathrm{K}^{+}$and $\mathrm{Cl}^{-}$content in some biological samples where a comparison was made between the results obtained by electrometry with liquid ion exchanger microelectrode and those by customary methods, flame photometry for $\mathrm{K}^{+}$, and coulombmetric titration for $\mathrm{Cl}^{-}$. The electrometry of an ion shows the ionic activity, whereas flame photometry or titrometry shows the total chemical concentration of the ion. The ratio between the ionic activity to the total concentration represents an activity coefficient of the ions in the sample. The human sera used were collected from patients in our hospital, and frog sera were those of bullfrogs, the latter being comparable to artificial frog Ringer solu- 
Table 7. Determination of potassium or chloride activities in biological samples with double-barreled $\mathrm{K}^{+}$and $\mathrm{Cl}^{-}$ion-selective microelectrodes.

\begin{tabular}{|c|c|c|c|c|c|}
\hline \multirow{2}{*}{ Samples } & \multicolumn{2}{|c|}{ Electrometry } & \multirow{2}{*}{$\begin{array}{c}\mathrm{K}^{+} \text {flame } \\
\text { photometry }\end{array}$} & \multirow{2}{*}{$\underset{\text { titration }}{\mathrm{Cl}^{-}}$} & \multirow{2}{*}{$\begin{array}{l}\text { Mean activity } \\
\text { coefficient }\end{array}$} \\
\hline & $\mathrm{K}^{+}$activity & $\mathrm{Cl}^{-}$activity & & & \\
\hline Human serum (10) & $3.95 \pm 0.38$ & $76.7 \pm 5.2$ & & & \\
\hline Frog serum (10) & $2.72 \pm 0.51$ & $68.7 \pm 2.5$ & $3.69 \pm 0.67$ & $90.5 \pm 4.3$ & $0.748 \pm 0.014$ \\
\hline Frog Ringer (10) & $2.60 \pm 0.06$ & $78.3 \pm 3.3$ & $3.50 \pm 0.09$ & $105.0 \pm 1.3$ & $0.745 \pm 0.003$ \\
\hline Egg white (5) & $43.6 \pm 4.2$ & $57.2 \pm 11.2$ & $57.5 \pm 5.7$ & $72.9 \pm 8.6$ & $0.772 \pm 0.019$ \\
\hline
\end{tabular}

tion. Since chicken egg yolk is not homogeneous, egg white was used for preparation of a protein-rich solution. The calculated values of the activity coefficients of all the samples were sufficiently close to 0.75 . This is essentially the same as the value of ROBINSON and STOKES (1970): i.e., 0.75 and 0.74 for the ionic strength of 0.125 and 0.150 of physiological saline solution.

\section{Electrochemical profile of the proximal tubule of bullfrog kidney}

Figure 7 illustrates the electrochemical profile of a renal proximal tubule of the bullfrog. Double-barreled ion-selective microelectrodes were advanced into the cell or tubular lumen in vivo, and individual outputs of $E_{\mathrm{Mem}}$ and $E_{\mathrm{ionic}}(=$

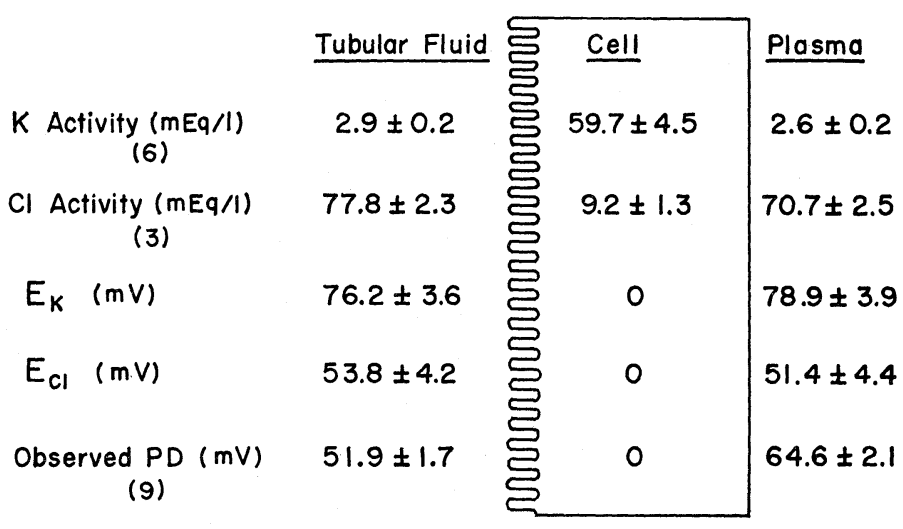

Fig. 7. Electrochemical profile of the bullfrog proximal tubule. The values are presented as mean \pm S.D. (n) is number of observations. The PD's are given with respect to the cell interior of $0 \mathrm{mV}$.

$E_{\mathrm{T}}-E_{\mathrm{Mem}}$, see METHODS and DISCUSSION) were recorded simultaneously in 9 successful experiments. For convenience, the potential level in the cell was expressed as $0 \mathrm{mV}$ in Fig. 7. The $\mathrm{PD}\left(E_{\mathrm{Mem}}\right)$ across the peritubular and brush border membrane was registered as 64.6 and $51.9 \mathrm{mV}$. The activity of $\mathrm{K}^{+}$in plasma, cell, and tubular fluid was, on the average, 2.6, 59.7 and $2.9 \mathrm{mEq} / 1 \mathrm{H}_{2} \mathrm{O}$, while that of $\mathrm{Cl}^{-}$was $70.7,9.2$, and $77.8 \mathrm{mEq} / 1 \mathrm{H}_{2} \mathrm{O}$, respectively. Therefore, the calculated 
$E_{\mathrm{K}}$ and $E_{\mathrm{C} 1}$ (Nernst potential) across the peritubular border were 78.9 and $51.9 \mathrm{mV}$, whereas those across the brush border were 76.2 and 53.8, respectively. By comparing $E_{\mathrm{K}}$ or $E_{\mathrm{C} 1}$ with the observed $\mathrm{PD}\left(E_{\mathrm{Mem}}\right)$, one can tell the direction and size of the electrochemical gradient across the individual membrane with respect to the test ionic species. For example, since $\mathrm{Cl}^{-}$is known to be reabsorbed across the tubule, it must enter the cell first across the brush border, and then be transported to the blood across the peritubular border. It is evident from Fig. 7, that $\mathrm{Cl}^{-}$can enter the cell across the brush border passively, or without any significant electrochemical gradient $(53.8-51.9=1.9 \mathrm{mV}$, a value being insignificant), and then it is transferred to the blood across the peritubular border(s) along a favorable electrochemical gradient of $13.2(64.6-51.4) \mathrm{mV}$. However, for net $\mathrm{K}^{+}$reabsorption $\mathrm{K}^{+}$must be pumped into the proximal tubular cell across the brush border against an electrochemical gradient of $24.3(76.2-51.9) \mathrm{mV}$, and then be transported to the blood across the peritubular membrane along a gradient of $14.3(78.9-64.6) \mathrm{mV}$. This indicates that at least in the course of $\mathrm{K}^{+}$reabsorption along the proximal tubule, some active process must be involved. Accordingly, the above data suggest that $\mathrm{Cl}^{-}$is reabsorbed passively across the proximal tubule, while $\mathrm{K}^{+}$ must be pumped across the brush border during the first step of its reabsorptive process.

\section{DISCUSSION}

In the present study, we have developed a reliable technique of fabricating double-barreled ion-selective microelectrodes where one barrel is a PD sensor and another a chemical or ionic sensor. A tip diameter of less than $1 \mu$ makes them suitable for measuring the electrical PD and ionic activity inside the cell. They are also useful for in situ measurement of ionic activity or concentration in most biological materials containing protein, glucose, and urea. Though some technical aspects of single- or double-barreled ion-selective microelectrode have been reported by previous workers (VYSKOCIL and KRIZ, 1972; WALKER, 1971; WrIGHT and MCDOUGAL, 1972; ZeUTHEN et al., 1974), still there are various problems in the practical use of these electrodes.

For practical use of the ion-selective microelectrodes in the intracellular measurement of ionic activity, the following problem must be taken into account. The potential change of an electrode that is inserted intracellularly is the sum of the electrical potential difference across the membrane $\left(E_{\mathrm{Mem}}\right)$ and of the change in electrode potential $\left(E_{\mathrm{ionic}}\right)$ due to the differences in ionic activity at the electrode tip. To determine the $E_{\text {ionic }}$ across the membrane one has to subtract the membrane $\mathrm{PD}, E_{\mathrm{Mem}}$, from the total potential output of the ion-selective microelectrode, $E_{\mathrm{T}}$. For this purpose, the use of a double-barreled microelectrode is advantageous because the net change in $E_{\text {ionic }}$ can be recorded by a differential output of the double-barreled microelectrode in which one barrel represents $E_{\mathrm{T}}$ and the other $E_{\text {Mem }}$. It should be emphasized, however, that on impaling cells with a single- 
barreled microelectrode, $E_{\mathrm{Mem}}$ and $E_{\mathrm{ionic}}$ always tend to cancel out each other, resulting in little change in the total potential output $\left(E_{\mathrm{T}}\right)$ by the ion-selective microelectrode. This is due to the fact that the membrane PD $\left(E_{\mathrm{Mem}}\right)$ with a negative cell interior results from the outward diffusion of $\mathrm{K}^{+}$from the cell or the inward diffusion of $\mathrm{Cl}^{-}$into the cell, both driven by the concentration difference across the cell membrane. Therefore, $E_{\mathrm{Mem}}$ always appears in such a direction that the ionic diffusions are restrained: namely, the more $\mathrm{K}^{+}$or the less $\mathrm{Cl}^{-}$ present within the cell, the more negative potential is generated inside the cell. In contrast, the tip of the ion-selective microelectrode directly reflects the level of ionic concentration at the local site: namely, the higher the $\mathrm{K}^{+}$or the lower the $\mathrm{Cl}^{-}$ present within the cell, the more is the positive potential recorded in the cell interior. This suggests that $E_{\mathrm{Mem}}$ and $E_{\mathrm{ionic}}$ always tend to offset changes in each other wherever the electrode tip is located. When using a single-barreled microelectrode, the above refractoriness of the electrode potential would certainly make it difficult to be sure of proper tip position, as well as the estimation of ionic activity.

There are several points that should be mentioned with respect to liquid membrane electrodes in general. The liquid-liquid interface is movable and it may sometimes be subject to stirring effects, pressure differentials, and thermal effects. Its mobility may lead to the contamination of liquid material with the test substance, and vice versa. In practical use, these instabilities would shorten the life of these electrodes. Relative mobilization and mechanical fragility of liquid-liquid interfaces have been partially reduced by mounting the liquid membrane material on the inside of the tip of glass micropipettes. Still they undergo the effects of hydrostatic pressure, osmotic pressure, and electrosmosis (or the fluid mobilization with the current applied to the electrode) in the external and internal environment around the tip. These problems are often encountered during the processes of resistance checking, calibration, storage and actual measurement. Miniaturization of the electrode tip could eliminate these shortcomings to some degree, but the technical difficulty in the fabrication of the electrodes increases progressively. Especially, the electrical resistance of a liquid ion exchanger microelectrode is extremely high, often well above $10^{10} \Omega$. As pointed out in Table 5, one of the key points in the successful fabrication of electrodes is the lowering of electrode resistance. The electrical resistance of the ionic barrel usually dominates that of the PD barrel and limits the usefulness of the entire assembly of doublebarreled ion-selective microelectrode systems. For an exact recording of two different electrical outputs in parallel drawn from a common spot, and for precise differentiation of one from another, complete isolation of the individual inputs is essential. This means that an extremely high input-impedance electrometer is necessary not only for the ionic barrel but also for the PD barrel. In case of highimpedance electrometry one must take into consideration the noise generated from internal and external sources, such as electronic devices and the electrode itself. 
The noise in microelectrodes has been shown by JoHnson (1928) and GesTeland and his associates (1958) to be proportional to the square root of pure electrode resistance, absolute temperature, and frequency. ZEUTHEN and his co-workers (1974) reported a low frequency noise of about $0.1 \mathrm{~Hz}$ with an amplitude of 0.3 to $1 \mathrm{mV}$ in the ionic barrel. The use of thin-walled glass capillaries, as in the present study, may serve to reduce the electrical resistance, but the mechanical fragility of glass tips itself will increase simultaneously. The sharpening of the electrode tip with a micro-grinder until the tip diameter is less than $1 \mu$ serves not only to lower the resistance but also to facilitate the penetration of the cell membrane in the intracellular measurements.

Temperature effects on liquid ion exchanger electrodes consist of several components including 1) the effect on the ionic activity of test solutions and 2) the effect on the EMF of the electrode, the latter further involving the effect of thermodynamic potentiality of exchanging ions as well as the physicochemical behavior of organic solvent as well as solutes in the liquid ion exchanger. Our experimental results led to the conclusion that all the measurements should be carried out under the same conditions where calibrations were to be made.

It is generally known that the anion-selective microelectrode potential is insensitive to cationic substitution at a constant ionic strength and similarly the cation-selective microelectrode potential is insensitive to anionic substitution. However, certain ionic species interfere with other ionic species thus distorting the EMF of the electrode. To avoid problems of this nature, solutions and materials used for the system or assembly should be prepared carefully to exclude inclusion of substances that could cause interference. Calibration should be carried out in solutions of the same general chemical composition as the solutions where measurements are to be performed. Further, the measurement of ionic activity should be interposed between calibrations immediately before and after sample measurements, and should be made on an adjustment of the ionic strength under a constant temperature. Strong acidic or basic samples can damage sensitive membranes. To avoid such difficulties, measurements should be done quickly and the whole system should be kept as clean as possible.

Organic ions found in biological fluids or added externally to the system may sometimes interfere with the EMF. We found in the course of our animal experiments that lissamine green, a marker of renal tubular flow in micropuncture study, causes a distortion in the EMF of the $\mathrm{Cl}^{-}$ion-selective microelectrode. Ethacrynic acid, a potent diuretic drug, interferes with the $\mathrm{Cl}^{-}$reading, and Harmaline, an inhibitor of $\mathrm{Na}^{+}-\mathrm{K}^{+}$activated ATPase, distorts the $\mathrm{K}^{+}$reading. Oily materials, such as liquid paraffine, are of no use to a liquid ion exchanger microelectrode, and high concentrations of protein cause serious damage to the liquid ion exchanger. Glycoproteins or mucous substances, because of the high density of their negative charge and strong adhering nature, often spoil the tip of the ion-selective microelectrode in biological applications. Since protein is an ampholyte, it might 
behave as an ion of either electrode. Figure 5 clearly indicates that $1 \mathrm{~mm}$ of bovine serum albumin caused a significant deviation of the EMF readings only under a circumstance where concentration of the test ion was very low. This may be the case of an $\mathrm{Cl}^{-}$ion-selective microelectrode applied to intracellular fluid, where the activity of $\mathrm{Cl}^{-}$is low while those for other organic anions are high. Despite many vulnerable points, the applicability of the $\mathrm{Cl}^{-}$ion-selective microelectrode to intracellular $\mathrm{Cl}^{-}$measurement remains to be explored by technical improvements since no other direct method for cell $\mathrm{Cl}^{-}$determination has been developed so far. Though the total sum of the organic anions within the cell can not exceed $10^{-1} \mathrm{M}$ by much, our findings suggested that the EMF of the $\mathrm{Cl}^{-}$ion-selective microelectrode may be possibly affected in such a way that the anions react as if $\mathrm{Cl}^{-}$is larger than in reality. Judging from our experience (Figs. 2, 6, and 7 and Table 7), however, the size of such an anion effect on intracellular $\mathrm{Cl}^{-}$estimation is presumed to be less than a few $\mathrm{mEq} / 1$. Bicarbonate ion in the cell would also play only a minor role in $\mathrm{Cl}^{-}$reading, because its concentration is generally low $\left(\left[\mathrm{HCO}_{3}\right]_{\mathrm{i}}=\right.$ 4-15 mEq/1: e.g., $4.8 \mathrm{mEq} / 1$ by BurNell (1968) for dog skeletal muscle; 14.7 $\mathrm{mEq} / 1$ by CLANCY and BROWN (1966) for dog cardiac and skeletal muscles; 11.1 $\mathrm{mEq} / 1$ by KHuRI et al. (1974c) for proximal tubule cells of Necturus; $10.3 \mathrm{mEq} / 1$ by KHURI et al. (1976) for rat skeletal muscle). An overestimation of $\mathrm{Cl}^{-}$due to intracellular $\mathrm{HCO}_{3}^{-}$may usually be less than $1 \mathrm{mEq} / 1$. In the present experiments, intracellular $\mathrm{Cl}^{-}$activity was estimated to be $9.2 \mathrm{mEq} / 1$ in the bullfrog tubule cell (Fig. 7), the error inherent in the process of estimation being less than a few $\mathrm{mEq} / 1$ (Fujimoto et al., 1977). The above argument may validate our tentative conclusion that the estimates derived from intracellular measurement of $\mathrm{Cl}^{-}$with double-barreled microelectrodes are reasonable unless other more suitable methods can be developed.

The authors wish to thank Dr. A. Hishida, Department of Internal Medicine, University of Tokyo, and Dr. T. Naotsuka, Department of Internal Medicine, Nagoya University for their cooperation in this study, and Prof. Gerhard Giebisch, Department of Physiology, Yale University, and Prof. Hisato Yoshimura, Department of Physiology, Hyogo Medical College for their careful reading of and comments on the manuscript.

\section{REFERENCES}

BAtes, R. G. (1964) Determination of pH. John Wiley \& Sons, New York.

BuRnell, J. M. (1968) In vivo response of muscle to changes in $\mathrm{CO}_{2}$ tension or extracellular bicarbonate. Am. J. Physiol., 215: 1376-1383.

Clancy, R. L. and Brown, E. B. (1966) In vivo $\mathrm{CO}_{2}$ buffer curves of skeletal and cardiac muscle. Am. J. Physiol., 211: 1309-1312.

EIsENMAN, G. (ed.) (1967) Glass Electrodes for Hydrogen and Other Cations. Dekker, New York.

Ferris, C. D. (1974) Introduction to Bioelectrodes. Plenum Press, New York \& London.

Fujimoto, M., Kubota, T., and Kotera, K. (1977) Electrochemical profile of $\mathrm{K}$ and $\mathrm{Cl}$ ions across the proximal tubule of bullfrog kidneys. A study using double-barreled ion-sensitive 
microelectrodes. In: Contributions to Nephrology, Karger, Basel, 6: No. 11.

Gesteland, R. C., Howland, B., Lettuin, J. Y., and Pitts, W. H. (1958) Comments on microelectrodes. Proc. Inst. Radio. Eng., 47: 1856-1862.

Johnson, J. B. (1928) Thermal agitation of electricity in conductors. Physiol. Rev., 32: 97-109.

Khuri, R. N., Agulian, S. K., and Kalloghalian, A. (1972) Intracellular potassium in cells of the distal tubule. Pflügers Arch., 335: 297-308.

Khuri, R. N., Agulian, S. K., and Bogharian, K. (1974a) Electrochemical potentials of chloride in distal tubule of the rat. Am. J. Physiol., 227: 1352-1355.

KhURI, R. N., Bogharian, K. K., and Agulian, S. K. (1974b) Intracellular bicarbonate in single skeletal muscle fibers. Pflügers Arch., 349: 285-294.

Khuri, R. N., Agulian, S. K., Bogharian, K., Nassar, R., and Wise, W. (1974c) Intracellular bicarbonate in single cells of Necturus kidney proximal tubule. Pflügers Arch., 349: 295-299.

KhuRI, R. N., Agulian, S. K., and Bogharian, K. K. (1976) Intracellular bicarbonate of skeletal muscle under different metabolic states. Am. J. Physiol., 230: 228-232.

Robinson, R. A. and Stokes, R. H. (1970) Electrolyte Solutions, 2nd ed. Butterworth, London.

VYSKOCIL, F. and KRIZ, N. (1972) Modification of single and double-barrel potassium specific microelectrodes for physiological experiments. Pflügers Arch., 337: 265-276.

Walker, J. L. (1971) Ionic specific liquid ion exchanger microelectrodes. Anal. Chem., 43: 89A-93A.

WrIGHT, F. S. and McDougal, W. S. (1972) Potassium-specific ion exchanger microelectrodes to measure $\mathrm{K}^{+}$activity in the renal distal tubule. Yale J. Biol. Med., 45: 373-383.

Zeuthen, T., Hiam, R. C., and Silver, I. A. (1974) Microelectrode recording of ion activity in brain. In: Ion-Selective Electrodes. ed. by Berman, H. J. and Herbert, N. C. Adv. Exp. Med. Biol., 50: 145-156. Plenum Press, New York \& London. 